\title{
A Relação entre os Estilos Parentais e o Engajamento Escolar
}

\author{
Jérssia Laís Fonsêca dos Santos \\ Núcleo de Estudos do Desenvolvimento Humano, Educacional e Social da Universidade \\ Federal da Paraíba, João Pessoa, Paraíba, Brasil \\ Patrícia Nunes da Fonsêca ${ }^{1}$ \\ Departamento de Psicopedagogia e Pós-Gradução em Psicologia Social da Universidade \\ Federal da Paraíba, João Pessoa, Paraíba, Brasil \\ Tamíris da Costa Brasileiro \\ Universidade Federal da Paraíba, João Pessoa, Paraíba, Brasil \\ Patrícia Oliveira de Andrade \\ Nájila Bianca Campos Freitas \\ Núcleo de Estudos do Desenvolvimento Humano, Educacional e Social da Universidade \\ Federal da Paraíba, João Pessoa, Paraíba, Brasil
}

\section{Resumo}

O presente estudo objetivou conhecer a correlação entre as dimensões (responsividade e exigência) dos estilos parentais e o engajamento escolar. Participaram 313 estudantes, com idade média de 15,76 anos $(D P=1,50)$. A maioria do sexo feminino $(55,6 \%)$ e de escola pública $(77 \%)$. Os participantes responderam o Questionário de Percepção dos Pais, Escala de Engajamento Escolar e um questionário sociodemográfico. Os resultados mostraram que a dimensão responsividade dos estilos parentais maternos se correlacionou com o fator geral da escala de engajamento escolar $(r=0,25 ; p<0,01)$ e os fatores vigor $(r$ $=0,24 ; p<0,01)$, absorção $(r=0,21 ; p<0,01)$ e dedicação $(r=0,20 ; p<0,01)$. Analisando os resultados da MANOVA, observou-se que as dimensões (responsividade e exigência) dos estilos parentais maternos não apresentaram nenhum efeito estatisticamente significativo, ao contrário do que aconteceu com a escala de engajamento escolar, onde se verificou diferenças significativas na escolaridade [Lambda de Wilks $=0,81, F(20,979)=3,10, p<0,001$, tamanho do efeito $=0,05]$, indicando que os participantes do $2^{\circ}$ ano do ensino médio obtiveram maiores médias nos fatores dedicação, absorção e no fator geral. Conclui-se que há necessidade de um trabalho pedagógico de orientação aos pais no sentido de informar a importância do papel da responsividade parental na dedicação dos filhos com as atividades escolares.

Palavras-chave: Estilos parentais, engajamento escolar, adolescentes.

\section{The Relation between Parenting Styles and School Engagement}

\author{
Abstract \\ The present study aimed to know the correlations between the dimensions (responsiveness and demand) \\ of parenting styles and school engagement. Participants were 313 students, average age of 15.76 (SD \\ Endereço para correspondência: Departamento de Psicopedagogia, Universidade Federal da Parába, Centro \\ de Educação, Campus I, Cidade Universitária, Castelo Branco, João Pessoa, PB, Brasil 58051-900. E-mail: \\ patynfonseca@hotmail.com \\ O presente artigo contou com apoio do Conselho Nacional de Desenvolvimento Científico e Tecnológico \\ (CNPq) por meio de bolsas de Mestrado e de Iniciação Científica concedidas ao terceiro e quarto autores, \\ respectivamente. Os autores agradecem a esta instituição.
}


$=1.50)$. Majority were females $(55.6 \%)$ and from public school $(77 \%)$. The participants answered the Parental Perception Questionnaire, School Engagement Scale and a sociodemographic questionaire. The results showed that the dimension responsiviness of maternal parenting styles correlated with the general factor of the School Engagement Scale $(r=.25 ; p<.01)$ and the factors vigor $(r=.24 ; p<.01)$, absorption $(r=.21 ; p<.01)$ and dedication $(r=.20 ; p<.01)$. Analyzing the results from MANOVA, were observed that the dimensions (responsiveness and demand) of the maternal parenting styles did not present any significant statistic effect, contrary to what happened to the School Engagement Scale, where significant differences were found in the education level [Wilk's lambda $=.81, F(20.979)=3.10$, $p<.001$, effect size $=.05$ ], indicating that participants from $2^{\circ}$ year of high school had higher average in the factors dedication and absorption and the general factor. Concludes that there is need for a pedagogic work of orientation for the parents to inform the importance role of parental responsiveness in the dedication of the children in the school activities.

Keywords: Parenting styles, school engagement, adolescents.

\section{La Relación entre los Estilos Parentales y la Implicación Escolar}

\section{Resumen}

El presente estudio tiene por objetivo conocer la correlación entre las dimensiones (responsividad y exigencia) de los estilos parentales y el compromiso escolar. Participaron 313 estudiantes, con edad promedio de 15.76 años $(S D=1.50)$. La mayoría del sexo femenino $(55.6 \%)$ y de escuela pública $(77 \%)$. Los participantes respondieron el Cuestionario de Percepción de los Padres, Escala de Compromiso Escolar y un cuestionario sociodemográfico. Los resultados mostraron que la dimensión responsividad de los estilos parentales maternos se correlacionó con el factor general de la escala de compromiso escolar $(r=.25 ; p<.01)$ y los factores vigor $(r=.24 ; p<.01)$, absorción $(r=.21 ; p<.01)$ y dedicación $(r=.20$; $p<.01$ ) Analizando los resultados de la MANOVA, se observó que las dimensiones (responsividad y exigencia) de los estilos parentales maternos no presentaron ningún efecto estadísticamente significativo, al contrario de lo que ocurrió con la escala de compromiso escolar, donde se verificaron diferencias significativas en la escolaridad [Lambda de Wilks $=.81, F(20,979)=3.10, p<.001$, tamaño del efecto $=.05]$, indicando que los participantes del $2^{\circ}$ año de enseñanza media obtuvieron mayores promedios en los factores dedicación, absorción y en el factor general. Se concluye que existe la necesidad de un trabajo pedagógico de orientación a los padres en el sentido de informar la importancia del papel de la responsividad parental en la dedicación de los hijos con las actividades escolares.

Palabras clave: Estilos parentales, compromiso escolar, adolescentes.

A família é o primeiro contexto de socialização da criança, porquanto modela o repertório comportamental infantil a partir das relações que os pais mantêm com os filhos, especificamente, através do nível de responsividade e exigência que esses demonstram no processo educacional. Deste modo, os estudos (Dessen \& Polônia, 2007; Formiga, 2011; Maccoby \& Martin, 1983; Pacheco, Teixeira, \& Gomes, 1999; Salvador, 2007) realizados ao longo das últimas décadas apontam o impacto dos estilos parentais no comportamento infanto-juvenil, de modo particular, no que se refere a promoção ou proteção das condutas antissociais (Santos, 2008).

Os estilos parentais correspondem a um conjunto de comportamentos que os pais adotam no processo de socialização dos filhos (Kobarg, Vieira, \& Vieira, 2010); isto é, compreendem a forma como os pais lidam com as questões de poder e hierarquia na relação com as crianças e adolescentes, as posições que adotam frente aos problemas disciplinares, ao controle do comportamento e à tomada de decisões (Hennigen, 1994). 
Maccoby e Martin (1983) propõem um modelo em que os estilos parentais estão vinculados à existência de duas dimensões: exigência (controle e monitoramento do comportamento dos filhos) e responsividade (afeto, envolvimento e aceitação dos filhos). A combinação dessas duas dimensões define os quatro estilos parentais. Assim, pais com altos escores em ambas dimensões são classificados como autoritativos, ao contrário daqueles que apresentam baixos escores, que são denominados de negligentes; pais com altos escores em exigência, mas baixos em responsividade são nomeados autoritários; por sua vez, pais com elevados escores em responsividade e baixos em exigência são classificados como permissivos (Paiva \& Ronzani, 2009).

Estudos revelam que os filhos de pais autoritativos geralmente apresentam melhor desempenho nos estudos e maior grau de otimismo. Os filhos que vivem no contexto autoritário também tendem a apresentar um bom desempenho escolar, porém possuem pouca habilidade social e baixa autoestima (Weber, Prado, Brandenburg, \& Viezzer, 2004). Os filhos de pais permissivos apresentam melhores resultados no desenvolvimento psicossocial, mas demonstram baixo desempenho escolar e maior aderência ao uso de drogas (Reppold, 2001). Já os filhos de pais negligentes apresentam-se com mais comportamentos antissociais, baixa autoestima e alto índice de fracasso escolar (Formiga, 2011; Pacheco et al., 1999).

Uma pesquisa realizada por Campos (2006) revelou que os pais de adolescentes que mantêm um equilíbrio entre os níveis de responsividade e exigência criam ótimas condições para que seus filhos obtenham um melhor desempenho escolar, diferentemente daqueles pais que se localizam nos extremos das dimensões dos estilos parentais (autoritário e permissivo). Sendo assim, os resultados do estudo apontam que os piores rendimentos escolares estavam relacionados aos adolescentes com pais com estilo negligente enquanto que para os melhores, o estilo predominante foi o autoritativo. Resultados semelhantes são apresentados nos estudos de Gonçalves (2013) que sugerem que o estilo autoritativo é o que se associa mais fortemente ao sucesso esco- lar enquanto o estilo negligente é o que menos se relaciona, evidenciando assim, a importância do envolvimento parental no desempenho escolar dos alunos.

Salvador (2007) faz um resgate de diversos estudos internacionais e nacionais, compreendendo os anos 80, 90 e 2000, que relacionam as práticas e os estilos parentais com o desempenho acadêmico dos filhos. De acordo com a autora, as pesquisas sobre estilos parentais apontam que o estilo autoritativo está associado ao melhor desempenho acadêmico, enquanto que os estilos autoritário e negligente estão associados ao baixo desempenho.

Portanto, percebe-se que o envolvimento dos pais tem efeitos significativos no desenvolvimento acadêmico dos filhos. Pais mais envolvidos no processo educacional dos filhos os motivam a se engajarem nos trabalhos escolares, fato que os conduzem a um melhor rendimento na escola. Nessa perspectiva, destaca-se a importância dos estilos parentais no engajamento escolar dos estudantes.

De acordo com Fredericks, Blumenfeld e Paris (2004), o engajamento escolar sofre influência das características individuais do estudante, mas também do contexto social e familiar do qual o mesmo está inserido. Sendo assim, estudar a relação do engajamento escolar com os estilos parentais vem informar o quanto a relação dos pais com os filhos podem estar estimulando ou impedindo o envolvimento acadêmico do aluno com as atividades escolares.

O engajamento é um conceito que se refere à relação que o estudante estabelece com as atividades escolares que lhes são propostas. Essa relação é influenciada pela interação entre o estudante e o contexto no qual a atividade ocorre, envolvendo aspectos comportamentais, emocionais e cognitivos (Fredericks et al., 2004). Smalls (2008) relaciona o engajamento escolar às atitudes dos estudantes no envolvimento das situações em sala de aula e a sua persistência nas tarefas escolares, enfatizando que o engajamento não se restringe apenas ao ambiente da sala de aula.

Para Schaufeli, Salanova, González-Romá e Bakker (2002) o engajamento escolar refere-se a 
um estado afetivo-cognitivo constituído por três fatores: o vigor, a dedicação e a absorção. $\mathrm{O}$ vigor está relacionado à energia, persistência e ao desejo de se esforçar no trabalho ou na atividade realizada; a dedicação refere-se ao sentimento de significado, entusiasmo, inspiração e interesse pela tarefa; e a absorção, por sua vez, implica em estar plenamente concentrado e feliz na realização da atividade (Bakker, Schaufeli, Leiter, \& Taris, 2008). Estes fatores são considerados como elementos-chave para o engajamento em uma atividade, pois, tal como ressaltam Schaufeli, Taris e Bakker (2006), as pessoas engajadas em uma atividade mostram-se esforçadas (vigor), envolvidas (dedicação) e se sentem felizes (absorção) em relação àquilo que estão fazendo.

Carter, McGee, Taylor e Williams (2007) analisaram a associação entre o engajamento dos adolescentes na escola e a relação mantida com a família. Os resultados indicaram uma relação significativa entre a família e o engajamento escolar, pois à medida que os adolescentes demonstravam maior envolvimento com a família evidenciam-se níveis mais elevados de engajamento escolar. Pomerantz, Moorman e Litwack (2007) também constataram que o envolvimento comportamental dos pais promove a motivação e o engajamento do aluno na escola, aumentando, assim, seu desempenho escolar.

Um estudo realizado por Smalls (2008) analisou se o estilo parental autoritativo das mães reforça o engajamento dos jovens nas atividades de classe e persistência nas tarefas escolares. Os resultados apontaram que o engajamento foi associado positivamente aos adolescentes que percebiam suas mães com o estilo autoritativo, em contraste, aqueles que não viam suas mães com esse estilo apresentaram baixos níveis de engajamento. As pesquisas de Steinberg, Lamborn, Dornbusch e Darling (1992) também comprovam que o estilo parental autoritativo tem um impacto significativo no desempenho escolar do adolescente, bem como no engajamento escolar.

Portanto, constatam-se, por meio dos estudos citados, evidências da relação entre os estilos parentais e o engajamento escolar, sobretudo no que se refere ao estilo parental autoritativo, o qual é visto na maioria das pesquisas como preditor de sucesso acadêmico. Nesse sentido, o presente estudo teve por objetivo correlacionar as dimensões dos estilos parentais (responsividade e exigência) com o engajamento escolar dos adolescentes.

\section{Método}

\section{Participantes}

Contou-se com a participação de 313 estudantes do município de João Pessoa (PB), com idades compreendidas entre 13 a 19 anos $(M=15,76 ; D P=1,50)$, sendo $55,9 \%$ do sexo feminino e $44,1 \%$ do sexo masculino. A maioria declarou residir com pai, mãe e irmãos $(58,8 \%)$. Os estudantes cursavam o $8^{\circ}$ ano $(15,3 \%)$ e o $9^{\circ}$ ano $(7,7 \%)$ do Ensino Fundamental e o $1^{\circ}$ $(23 \%), 2^{\circ}(22,4 \%)$ e $3^{\circ}(31,6)$ do Ensino Médio, onde $77 \%$ eram provenientes de escola pública e $23 \%$ de escola privada. Para determinação da amostra, utilizou-se um critério não probabilístico, amostragem acidental ou "por conveniência", participando aqueles adolescentes que apresentavam a idade entre 13 a 20 anos - pois para Papalia, Olds e Feldman (2010), a adolescência é uma fase do desenvolvimento que vai até aproximadamente 20 anos - e de acordo com sua disponibilidade, concordaram em participar do estudo.

\section{Instrumentos}

Os participantes responderam a um livreto em que constavam o questionário de percepção dos pais, a escala de engajamento escolar e um questionário solicitando informações sobre os dados sociodemográficos, os quais serão descritos a seguir:

Questionário de Percepção dos Pais. Trata-se de uma medida originalmente construída por Pasquali e Araújo (1998), composta por 20 itens para cada uma das versões, isto é, pai e mãe, sendo que a metade representa a dimensão responsividade (e.g., Fica feliz de me ver quando volto da escola ou de um passeio; Consola-me quando estou com medo) e a outra metade a dimensão exigência (e.g., Acha que deve me castigar para me corrigir e melhorar; Fica sempre me lembrando das coisas que não posso fazer). 
Para cada item utiliza-se uma escala de resposta de cinco pontos, variando de $0=$ Nada aplicável a 4 = Totalmente aplicável. Pasquali et al. (2012) encontraram evidências de que o instrumento é bifatorial. A versão materna explicou $37,9 \%$ da variância total e os coeficientes de consistência interna (alfas de Cronbach) foram 0,84 para responsividade e 0,73 para exigência. A versão paterna explicou $41,4 \%$ da variância total e os coeficientes de consistência interna (alfas de Cronbach) foram 0,86 e 0,85 para responsividade e exigência, respectivamente.

Cabe ressaltar que no presente estudo utilizou-se apenas a versão materna do questionário, levando em consideração que a maioria dos adolescentes convive com as mães, sobretudo nos casos de famílias monoparentais ou daquelas envolvidas em situações de divórcio e separação. Ademais, a mãe é identificada pelo adolescente como figura mais próxima e marcante que o pai. É com ela que os filhos estabelecem contatos mais íntimos e prolongados (Reichert \& Wagner, 2007).

Escala de Engajamento Escolar. Este instrumento foi construído originalmente na Holanda, onde a sua primeira versão foi elaborada para o contexto organizacional. Porém, em seguida, foi reconhecida a possibilidade de aplicá-lo, de modo satisfatório, também ao contexto educacional. $\mathrm{O}$ instrumento foi validado para o Brasil por Gouveia (2009). A escala é composta por 17 itens, divididos em três fatores: absorção (e.g. Item 3. O tempo passa voando quando estou realizando minhas tarefas como estudante), dedicação (e.g. Item 1. As minhas tarefas como estudante fazem-me sentir cheio(a) de energia) e vigor (e.g. Item. 4. Sinto-me com força e energia quando estou estudando ou vou às aulas). Estes são respondidos em escala de sete pontos, variando de $0=$ nunca a $6=$ sempre. A validação realizada em Maceió (AL) apresentou indicadores de ajuste considerados satisfatórios: $\mathrm{X}^{2}(116)$ $=435,17, p<0,001,{ }^{2} / g l=3,75, \mathrm{GFI}=0,942$, AGFI $=0,924, \mathrm{CFI}=0,942$ e RMSEA $=0,055$ (IC90\% $=0,050-0,061)$.

Questionário Sociodemográfico. Foram apresentadas algumas perguntas sobre as características dos participantes, com o intuito de caracterizar a amostra estudada, a saber: idade, sexo, escolaridade e tipo de escola (pública $v s$. privada).

\section{Procedimento}

O presente estudo foi avaliado e aprovado pelo Comitê de Ética em Pesquisa com Seres Humanos do Hospital Universitário Lauro Wanderley (CEP/HULM) sob o protocolo de $\mathrm{n}^{\circ} 400 / 11$, estando de acordo com todos os preceitos legais previstos na Resolução 196/2012. Inicialmente, manteve-se contato com as escolas, onde os diretores foram devidamente informados sobre os objetivos do estudo, assinando um Termo de Responsabilidade que autorizava a participação dos estudantes. Na oportunidade, foram agendadas visitas para aplicação dos instrumentos. Todos os participantes responderam os questionários individualmente em sala de aula. Durante a aplicação, os pesquisadores permaneceram na sala para esclarecer eventuais dúvidas, sendo facultada a presença do professor. $\mathrm{O}$ tempo médio de respostas aos instrumentos foi de aproximadamente 25 minutos.

\section{Análise dos Dados}

Os dados foram tabulados e analisados pelo PASW Statistics (Predictive Analytics Software), versão 18. Foram calculadas estatísticas descritivas (médias, desvios-padrão e percentagens) para caracterização e descrição do grupo amostral. Em seguida, foram realizadas as correlações de Pearson ( $r$ ), para verificar como se associavam os construtos estudados (Dimensão dos Estilos Parentais e Engajamento escolar) e uma MANOVA para ver o efeito das variáveis sociodemográficas na pontuação das escalas.

\section{Resultados}

Os resultados serão apresentados de acordo com o tipo de análise empregada para o tratamento de dados. Portando, inicialmente na correlação entre as dimensões dos estilos parentais maternos (responsividade e exigência) e o engajamento escolar verificou-se que houve correlação positiva entre a dimensão responsividade e 
os fatores da escala de engajamento escolar, a saber: fator geral $(r=0,25 ; p<0,01)$; vigor $(r$ $=0,24 ; p<0,01)$; absorção $(r=0,21 ; p<0,01) \mathrm{e}$ dedicação $(r=0,20 ; p<0,01)$; a dimensão exigência não apresentou correlação com nenhum dos fatores, como mostra a Tabela 1.

Tabela 1

Correlação entre as Dimensões dos Estilos Parentais Maternos e o Engajamento Escolar

\begin{tabular}{ccc}
\hline \multirow{2}{*}{ Engajamento Escolar } & Dimensões dos Estilos Parentais Maternos \\
\cline { 2 - 3 } & Responsividade & Exigência \\
\hline Vigor & $0,24^{*}$ & 0,06 \\
Absorção & $0,21^{*}$ & 0,07 \\
Dedicação & $0,20^{*}$ & 0,07 \\
Fator Geral & $0,25^{*}$ & 0,08
\end{tabular}

nota: ${ }^{*} p<0,01$ (teste de significância bicaudal, com eliminação dos casos em branco - missing - através do método pairwise).

Para verificar as diferenças das dimensões (responsividade e exigência) dos estilos parentais maternos e o engajamento escolar em função das variáveis sociodemográficas, efetuou-se uma MANOVA considerando as duas variáveis inter-sujeito: sexo (masculino e feminino) e escolaridade $\left(8^{\circ}\right.$ e $9^{\circ}$ anos do Ensino Fundamental e $1^{\circ}, 2^{\circ}$ e $3^{\circ}$ ano do Ensino Médio). Como variáveis-critério (dependentes) foram selecionadas as dimensões (responsividade e exigência) dos estilos parentais maternos e o engajamento escolar (dedicação, vigor, absorção e fator geral).

Analisando os efeitos de interação principal das variáveis sociodemográficas com as dimensões (responsividade e exigência) dos estilos parentais maternos não se observou nenhum efeito estatisticamente significativo, o que indica que o sexo e a escolaridade dos participantes não influenciaram nos níveis de responsividade e exigência das mães. Por outro lado, no que diz respeito ao engajamento escolar, os resultados indicam efeito estatisticamente significativo apenas na escolaridade [Lambda de Wilks = 0,81, $F(20,979)=3,10, p<0,001$, tamanho do efeito $=0,05]$. No que se refere a variável sexo, não houve diferenças significativas, indicando que tanto os meninos quanto as meninas apresentaram pontuações semelhantes em relação ao engajamento escolar. Esses resultados corroboram com o estudo realizado por Smalls (2008), que não encontrou efeito significativo do sexo no engajamento escolar dos adolescentes.

Com relação à escolaridade, os testes univariados indicaram haver diferença em relação ao fator dedicação $\left[F(4,299)=6,0, p<0,001, \eta^{2}\right.$ $0,07]$, com o teste post hoc de Bonferroni revelando que os participantes do $2^{\circ}$ ano do ensino médio obtiveram maior média $(M=4,52)$ do que o fizeram os alunos do $3^{\circ}$ ano $(M=4,22)$, do $1^{\circ}$ ano $(M=4,17)$, do $8^{\circ}$ ano do ensino fundamental $(M=3,67)$ e do $9^{\circ}$ ano $(M=3,53)$; e ao fator $A b$ sorção $\left[F(4,299)=4,87, p<0,001, \eta^{2} 0,06\right]$, com o teste post hoc de Bonferroni observou-se que os participantes do $2^{\circ}$ ano do ensino médio obtiveram maior média $(M=3,55)$ do que o fizeram os alunos do $3^{\circ}$ ano $(M=3,16)$, do $9^{\circ}$ ano do ensino fundamental $(M=2,88)$, do $1^{\circ}$ ano do ensino médio $(M=2,74)$, e do $8^{\circ}$ ano $(M=2,72)$. Também houve variação no Fator Geral da Escala de Engajamento Escolar $[F(4,299)=4,54, p<0,001$, $\eta^{2}$ 0,05], com o teste post hoc de Bonferroni encontrou-se que os participantes do $2^{\circ}$ ano do ensino médio obtiveram maior média $(M=3,76)$ do que o fizeram os alunos do $3^{\circ}$ ano $(M=3,40)$, do $1^{\circ}$ ano $(M=3,25)$, do $9^{\circ}$ ano do ensino fundamental $(M=3,09)$ e do $8^{\circ}$ ano $(M=2,94)$. 


\section{Discussão}

O presente estudo teve por objetivo correlacionar as dimensões dos estilos parentais (responsividade e exigência) com o engajamento escolar dos adolescentes. Especificamente, pretendeu-se verificar a interferência das variáveis sociodemográficas (sexo e escolaridade) no engajamento escolar e nas dimensões dos estilos parentais (responsividade e exigência). Para alcançar tais objetivos, foram calculadas estatísticas descritivas para caracterização do grupo amostral, correlações de Pearson ( $r$ ) para verificar como se associavam os construtos estudados (Dimensões dos Estilos Parentais e Engajamento escolar) e uma MANOVA para ver o efeito das variáveis sociodemográficas na pontuação das escalas.

De acordo com os resultados encontrados, pode-se considerar que há influência da dimensão responsividade do estilo parental materno no engajamento escolar dos adolescentes, o que evidencia a importância de tal variável no processo educacional dos jovens. Os resultados sugerem que quando as mães são sensíveis às necessidades de seus filhos, apoiando-os e provendo-lhes afeto, estes se sentem valorizados e apoiados emocionalmente, aspectos que favorecem a autoestima, a motivação e o engajamento escolar. Estes resultados, confirmados pela literatura, apontam que os filhos de pais (pai e mãe) autoritativos são mais ativos, responsáveis, independentes, autoconfiantes, engajados na escola e com bom desempenho acadêmico (Reppold, Pacheco, Bardagi, \& Hurtz, 2002; Smalls, 2008; Weber, Brandenburg, \& Viezzer, 2003; Weber et al., 2004, Weber, Selig, Bernardi, \& Salvador, 2006).

Portanto, pode-se compreender que relações com elevada afetividade e presença de comunicação entre mães e filhos favorecem o engajamento dos adolescentes nas atividades escolares, particularmente, a dedicação aos estudos e o estado de felicidade no cumprimento de suas tarefas. Nestes casos, as mães apresentam-se para os filhos como um recurso para realização dos seus desejos, fazendo com que eles sintam-se mais seguros, motivados e capazes de realizar suas próprias atividades escolares (Patias, Siqueira, \& Dias, 2013; Reppold et al., 2002; Weber et al., 2004).

Segundo Ferreira (2010) o aluno motivado realiza com mais intensidade suas atividades escolares, participa com maior entusiasmo dos desafios e apresenta-se mais comprometido. Moore, Husman e Brownlee (2003) afirmam que estudantes engajados são participantes ativos e construtores de suas aprendizagens. Procuram oportunidade para aprender mais e obter o entendimento profundo de seu aprendizado. Estas pessoas persistem em face das dificuldades e têm prazer com seu sucesso, se esforçando e se dedicando com entusiasmo às atividades escolares (Bakker et al., 2008), como forma de alcançarem um objetivo maior que é a aquisição de novos conhecimentos.

No que diz respeito às variáveis sociodemográficas, observou-se que o nível de escolaridade influencia na pontuação da escala de engajamento escolar. Quando comparadas as séries dos participantes, os estudantes do $2^{\circ}$ ano do ensino médio se mostraram mais engajados nas atividades escolares, obtendo maiores médias nos fatores Geral, Dedicação e Absorção da Escala de Engajamento Escolar. Este resultado contradiz as suposições de Megliato (2011) que diz que ao avançar das séries e da idade os níveis de motivação intrínseca tendem a diminuir, assim como o engajamento escolar. Porém, as pesquisas de Gouveia (2009) evidenciaram que a idade e o engajamento escolar não apresentam entre si uma correlação linear, demonstrando que dos 10 aos 14 anos o nível de engajamento parece diminuir, a partir de então ele tende a aumentar, sobretudo entre os 17 e 18 anos, período em que, geralmente, os adolescentes se encontram no Ensino Médio.

Visto que esses adolescentes estão em uma fase que demanda decisões sérias em suas vidas, como a escolha de uma profissão, a preparação para o vestibular, eles podem se mostrar mais engajados com as atividades escolares, as quais exigirão maior dedicação e absorção em relação aos estudos. De acordo com Schaufeli et al. (2002), os estudantes dedicados se identificam fortemente com o trabalho ou a atividade que 
estão desenvolvendo na sala de aula, sentindo-se orgulhosos do que estão fazendo e atribuindo significado a tarefa. Isto exigirá maior absorção em relação aos estudos, ou seja, os adolescentes passam a se concentrar totalmente na atividade, levando em consideração que o tempo passa rápido e que precisam desfrutar do que fazem. Os alunos que apresentam altas pontuações nestes fatores são intrinsecamente motivados e envolvidos no que fazem (Bakker et al., 2008; Schaufeli et al., 2002).

Neste sentido, esperava-se que os alunos do $3^{\circ}$ ano do ensino médio também se mostrassem mais engajados nas atividades escolares visto que estão mais próximos de prestar vestibular, bem como de decidir qual carreira seguir. Porém, nesta fase são pressionados pelos pais, professores e diretores, o que prejudica as emoções e ocasiona pouco envolvimento com as tarefas escolares. Faria (2008) ressalta que o essencial para o estudante nesta fase é o suporte emocional oferecido pelos profissionais da escola em colaboração com os pais. As relações positivas estabelecidas na sala de aula, bem como a presença da afetividade e da clareza de objetivos por parte dos professores e pais são elementos que podem potencializar o engajamento dos estudantes nas atividades. Ladd e Dinella (2009) afirmam que os alunos que recebem esse apoio e orientação se envolvem mais com a escola e com as atividades, o que culminaria com maiores níveis de realização escolar.

\section{Considerações Finais}

Diante do exposto, pode-se considerar que a relação que os pais, especificamente, as mães, estabelecem com os filhos influencia de forma positiva ou negativa no engajamento escolar dos estudantes, evidenciando a influência dos estilos parentais sobre seu processo educacional.

A dimensão responsividade dos estilos parentais está relacionada aos estilos autoritativo e permissivo, os quais apresentam alto nível de envolvimento e afetividade.

A dimensão exigência está presente em um nível elevado nos estilos autoritário e autoritativo. De acordo com Maccoby e Martin (1983), o equilíbrio entre a responsividade e a exigência define o estilo autoritativo, considerado um modelo de referência para a criação dos filhos.

De modo geral, os resultados apontaram que a dimensão responsividade influencia positivamente o engajamento escolar dos adolescentes. Isto revela que a atenção e a afetividade das mães, a participação nas atividades escolares, a valorização da autoexpressão e da autonomia favorecem o envolvimento dos filhos com a escola e, consequentemente, um bom desempenho acadêmico. Contrariamente, a dimensão exigência não apresentou correlação com o engajamento escolar, revelando que a cobrança excessiva das mães, a ausência de afetividade, a falta de diálogo não contribuem para um bom desempenho acadêmico dos estudantes, fazendo com que eles não se interessem e nem se engajem nas atividades escolares.

Portanto, parece que a afetividade dos pais, o envolvimento e o diálogo, comportamentos característicos dos estilos autoritativo são essenciais para que os filhos sintam-se motivados e interessados na escola como um todo. Por outro lado, é oportuno frisar que mesmo que os pais permissivos se comuniquem bem e se utilizem do diálogo, estes exigem pouco dos seus filhos, não controlam suas ações, nem impõem regras e limites, levando-os a agirem livremente segundo seus impulsos e vontades, além de que não os estimulam (Granetto, 2008), dificultando o interesse de estes se engajarem na escola.

Ademais, a ausência de afeto, de compreensão e o distanciamento parental, presentes nos estilos autoritário e negligente, parece não favorecer o desempenho dos filhos, prejudicando o engajamento escolar destes. Esses resultados corroboram com o já descrito em outros estudos, onde o estilo autoritativo apresenta melhores resultados em termos de desenvolvimento psicossocial e acadêmico (Bornstein \& Bornstein, 2011; Reppold, 2001; Salvador, 2007), enquanto os estilos autoritário, permissivo e negligente apresentam resultados negativos (Brodski, 2010; Pacheco et al., 1999; Reichert \& Wagner, 2007; Reppold \& Hurtz, 2003). Deste modo, fica evidente a importância da relação parental, da formação de vínculos e da afetividade para a pro- 
moção do engajamento escolar, o qual influencia positivamente a aprendizagem dos estudantes e o desempenho acadêmico.

Embora este estudo tenha alcançado os objetivos propostos, ressaltam-se algumas limitações. Um ponto relevante a ser destacado é que o presente estudo não contemplou uma amostra representativa da população de estudantes paraibanos, considerando o fato de que a pesquisa foi desenvolvida apenas em duas escolas da rede pública e duas da rede privada da cidade de João Pessoa. Portanto, os resultados aqui encontrados não podem ser generalizados para o restante da população. Sugere-se, desta forma, desenvolver estudos abarcando amostras maiores, para que os dados sejam mais homogêneos e condizentes com a realidade paraibana.

Em termos práticos, espera-se que este estudo possa contribuir para aprofundar a análise do tema acerca dos estilos parentais e o engajamento escolar, bem como para a prática de técnicos, proporcionando-lhes suporte teórico para uma intervenção mais eficaz com famílias e escolas. Além disso, sugere-se a criação de oportunidades que propiciem diálogo e orientação, no sentido de informar os pais e as escolas a importância do papel parental no processo educacional dos jovens.

\section{Referências}

Bakker, A. B., Schaufeli, W. B., Leiter, M. P., \& Taris, T. W. (2008). Work engagement: An emerging concept in occupational health psychology. Work \& Stress, 22(3), 187-200. doi:10.1080/02678370802393649

Bornstein, L., \& Bornstein, M. H. (2011). Estilos de práticas parentais e desenvolvimento social da criança. In R. E. Tremblay, M. Boivin, \& R. D. V. Peters (Eds.), Enciclopédia sobre o desenvolvimento na primeira infância (pp. 1-4). Montreal, Canadá: Centre of Excellence for Early Childhood Development.

Brodski, S. K. (2010). Abuso emocional: Suas relações com autoestima, bem-estar subjetivo e estilos parentais em universitários (Dissertação de mestrado em Psicologia do Desenvolvimento, Universidade Federal do Rio Grande do Sul, Porto Alegre, RS, Brasil). Recuperado em http://www.lume.ufrgs.br/bitstream/handle/ 10183/26809/000760983.pdf?sequence $=1$
Campos, A. E. R. (2006). Estilo parental percebido e desempenho escolar de adolescentes do Ensino Médio de duas escolas das redes pública e privada da cidade do Salvador (Bahia), Brasil. Revista Lusófona de Educação, 7, 192.

Carter, M., McGee, R., Taylor, B., \& Williams, S. (2007). Health outcomes in adolescence: Associations with family, friends and school engagement. Journal of Adolescence, 30(1), 51-62. doi:10.1016/j.adolescence.2005.04.002

Dessen, M. A., \& Polonia, A. C. (2007). A família e a escola como contextos de desenvolvimento humano. Paidéia (Ribeirão Preto), 17(36), 21-32. doi:10.1590/S0103-863X2007000100003

Faria, A. F. (2008). Engajamento de estudantes em atividade de investigação: Estudo em aula de Física do Ensino Médio (Dissertação de mestrado em Educação, Universidade Federal de Minas Gerais, Belo Horizonte, MG, Brasil). Recuperado em http://www.bibliotecadigital.ufmg.br/ dspace/bitstream/handle/1843/FAEC-84XHTF/ dissertacao_faria_a_f.pdf?sequence $=1$

Ferreira, E. E. B. (2010). A percepção de competência, autonomia e pertencimento como indicadores da qualidade motivacional do aluno (Tese de doutorado em Educação, Faculdade de Filosofia e Ciências, Universidade Estadual Paulista, Marília, SP, Brasil). Recuperado em http://www. marilia.unesp.br/Home/Pos-Graduacao/Educacao/Dissertacoes/ferreira_eeb_do_mar.pdf

Formiga, N. S. (2011). Estilo parental e condutas desviantes: Testagem de um modelo causal em jovens paraibanos - Brasil. Boletim Academia Paulista de Psicologia, 31(81), 465-484.

Fredericks, J. A., Blumenfeld, P. C., \& Paris, A. H. (2004). School engagement: Potential of the concept, state of evidence. Review of Educational Research, 74(1), 59-109. doi:10.3102/00346543074001059

Gonçalves, A. T. S. (2013). Estilos parentais e o seu impacto no sucesso escolar dos alunos: Um estudo numa escola TEIP 2 (Dissertação de mestrado em Psicologia, Universidade Fernando Pessoa, Porto, Portugal). Recuperado em http://bdigital.ufp.pt/bitstream/10284/3840/1/pronta.pdf

Gouveia, R. S. V. (2009). Engajamento escolar e depressão: Um estudo correlacional entre crianças e adolescentes (Tese de doutorado não-publicada em Psicologia Social, Universidade Federal da Paraíba, João Pessoa, PB, Brasil). 
Granetto, W. E. (2008). Práticas educativas parentais em dependentes químicos (Dissertação de mestrado, Pontifícia Universidade Católica de Campinas, SP, Brasil). Recuperado em http:// www.bibliotecadigital.puc-campinas.edu.br/ tde_busca/arquivo.php?codArquivo $=404$

Hennigen, I. (1994). Dimensões psicossociais da adolescência: Identidade, relação familiar $e$ relação com amigos (Dissertação de mestrado não-publicada em Psicologia, Universidade Federal do Rio Grande do Sul, Porto Alegre, RS, Brasil).

Kobarg, A. P. R., Vieira, V., \& Vieira, M. L. (2010). Validação da Escala de Lembranças sobre Práticas Parentais (EMBU). Avaliação Psicológica, 9(1), 77-85.

Ladd, G. W., \& Dinella, L. M. (2009). Continuity and change in early school engagement: Predictive of children's achievement trajectories form first do eight grade? Journal of Educational Psychology, 101(1), 190-206. doi:10.1037/a0013153

Maccoby, E., \& Martin, J. (1983). Socialization in the context of the family: Parent-child interaction. In E. M. Hetherington (Ed.), Handbook of child psychology: Vol. 4 (pp. 1-101). New York: Wiley.

Megliato, J. G. P. (2011). Perfis motivacionais e engajamento de adolescentes nas tarefas escolares em casa (Dissertação de mestrado em Educação, Universidade Estadual de Londrina, PR, Brasil). Recuperado em http://www.bibliotecadigital. uel.br/document $/$ ?code $=$ vtls000172051

Moore, W. P., Husman, M., \& Brownlee, H. (2003). Constructing youth engagement: A synthesis of literature, observation, and professional opinion the integration of youth engagement into the arts classroom. Retrieved from http://www. kcya.org/documents/ConstructingYouthEngagement.pdf

Pacheco, J. T. B., Teixeira, M. A. P., \& Gomes, W. B. (1999). Estilos parentais e desenvolvimento de habilidades sociais na adolescência. Psicologia: Teoria e Pesquisa, 15(2), 117-126.

Paiva, F. S., \& Ronzani, T. M. (2009). Estilos parentais e consumo de drogas entre adolescentes: Revisão sistemática. Psicologia em Estudo, 14(1), 177-183.

Papalia, D. E., Olds, S. W., \& Feldman, R. D. (2010). Desenvolvimento humano. Porto Alegre, RS: McGraw-Hill.
Pasquali, L., \& Araújo, J. M. A. (1998). Questionário de Percepção dos Pais - QPP. Psicologia, Teoria e Pesquisa2(1), 56-72.

Pasquali, L., Gouveia, V. V., Santos, W. S., Fonsêca, P. N., Andrade, J. M., \& Lima, T. J. S. (2012). Questionário de Percepção dos Pais: Evidências de uma medida de estilos parentais. Paidéia (Ribeirão Preto), 22(52), 155-164. doi:10.1590/ S0103-863X2012000200002

Patias, N. D., Siqueira, A. C., \& Dias, A. C. G. (2013). Práticas educativas e intervenção com pais: A educação como proteção ao desenvolvimento dos filhos. Mudanças - Psicologia da Saúde, 21(1), 29-40. doi:10.15603/2176-1019/ mud.v21n1p29-40

Pomerantz, E. M., Moorman, E. A., \& Litwack, S. D. (2007). The how, whom, and why of parents' involvement in children's academic lives. Review of Educational Research, 77(3), 373-410. doi:10.3102/003465430305567

Reichert, C. B., \& Wagner, A. (2007). Autonomia na adolescência e sua relação com os estilos parentais. Psico, 38(3), 292-299.

Reppold, C. T. (2001). Estilo parental percebido e adaptação psicológica de adolescentes adotados (Dissertação de mestrado em Psicologia, Universidade Federal do Rio Grande do Sul, Porto Alegre, RS, Brasil). Recuperado em http://www.lume.ufrgs.br/bitstream/handle $/ 10183 / 3559 / 000339902$.pdf? sequence $=1$

Reppold, C. T., \& Hurtz, C. S. (2003). Reflexão social, controle percebido e motivações à adoção: Características psicossociais das mães adotivas. Estudos de Psicologia (Natal), 8(1), 25-36. doi:10.1590/S1413-294X2003000100004

Reppold, C. T., Pacheco, J., Bardagi, M., \& Hurtz, C. S. (2002). Prevenção de problemas de comportamento e desenvolvimento de competências psicossociais em crianças e adolescentes: Uma análise das práticas educativas e dos estilos parentais. In C. S. Hutz (Ed.), Situações de risco e vulnerabilidade na infância e adolescência: Aspectos teóricos e estratégias de intervenção (pp. 7-51). São Paulo, SP: Casa do Psicólogo.

Salvador, A. P. V. (2007). Análise da relação entre práticas educativas parentais, envolvimento com tarefas escolares, depressão e desempenho acadêmico de adolescentes (Dissertação de mestrado em Educação, Universidade Federal 
do Paraná, Curitiba, PR, Brasil). Recuperado em http://www.ppge.ufpr.br/teses/M07_salvador. pdf

Santos, W. (2008). Explicando comportamentos socialmente desviantes: Uma análise do compromisso convencional e afiliação social (Tese de doutorado em Psicologia Social, Universidade Federal da Paraíba, João Pessoa, PB, Brasil). Recuperado em http://www.dominiopublico. gov.br/download/texto/cp097662.pdf

Schaufeli, W. B., Salanova, M., González-Romá, V., \& Bakker, A. B. (2002). The measurement of engagement and burnout: A two sample confirmatory factor analytic approach. Journal of Happiness Studies, 3, 71-92. doi:10.1023/A:1015630930326

Schaufeli, W. B., Taris, T. W., \& Bakker, A. B. (2006). Dr Jekyll or Mr Hyde? On the differences between work engagement and workaholism. In R. J. Burke (Ed.), Research companion to working time and work addiction (pp. 193-217). Cheltenham, GL: MPG Books.

Smalls, C. (2008). African American adolescent engagement in the classroom and beyond: The roles of mother's racial socialization and democratic-involved parenting. Journal of Youth and Adolescence, 38(2), 204-213.
Steinberg, L., Lamborn, S. D., Dornbusch, S. M., \& Darling, N. (1992). Impact of parenting practices on adolescent achievement: Authoritative parenting, school involvement, and encouragement to succeed. Child Development, 63(5), 12661281. doi:10.1111/j.1467-8624.1992.tb01694.x

Weber, L. N. D., Brandenburg, O. J., \& Viezzer, A. P. (2003). A relação entre o estilo parental e o otimismo da criança. Psico-USF, 8(1), 71-79.

Weber, L. N. D., Prado, P. M., Brandenburg, O. J., \& Viezzer, A. P. (2004). Identificação de estilos parentais: O ponto de vista dos pais e dos filhos. Psicologia: Reflexão e Crítica, 17(4), 323-332.

Weber, L. N. D., Selig, G. A., Bernardi, M. G., \& Salvador, A. P. V. (2006). Continuidade dos estilos parentais através das gerações-transmissão intergeracionais de estilos parentais. Paidéia (Ribeirão Preto), 16(35), 407-414. doi:10.1590/ S0103-863X2006000300011

Recebido: 25/07/2013

$1^{a}$ revisão: $23 / 01 / 2014$

$2^{a}$ revisão: $23 / 03 / 2014$

Aceite final: 28/03/2014 